\title{
Model of economic growth of the economy of small and medium-sized enterprises in the context of the spread of coronavirus infection
}

\author{
Alexey Ukhanov ${ }^{1}$, Alexander Chupin ${ }^{1, *}$, and Zhanna Chupina ${ }^{1}$ \\ ${ }^{1}$ Peoples' Friendship University of Russia (RUDN University), 117198, Miklukho-Maklaya str.6, \\ Moscow, Russia
}

\begin{abstract}
In the last three months, the dynamics of economic development began to decline, due to the influence of the pandemic. The world was not ready for the big challenge of nature. The article describes the state of small and medium-sized businesses, the state of the economy, the market and the market environment of the countries most affected by the spread of the coronavirus, and also describes the support measures taken by the state for these enterprises. The article presents a model of economic growth for small and medium-sized enterprises operating in the context of the new coronavirus infection.
\end{abstract}

\section{Introduction}

Each of us needs protection from the new coronavirus infection. Restaurants and shops, fitness centers, bakeries and many similar businesses are the most vulnerable part of the business today. Small business, although it is called "small", plays a huge role in the Russian economy. Small businesses in Russia include enterprises in which the number of people does not exceed 100 people, whose income is no more than 800 million rubles for the previous year (excluding VAT). Small businesses include about 6 million companies that employ almost 22 million people. Unfortunately, in recent months, events have developed according to a negative scenario. The category "medium business" includes enterprises in which the number of people does not exceed 250 people, whose income is no more than 2 billion rubles in the previous year (excluding VAT). The expenses of citizens on services in the field of small and medium-sized businesses during the spread of the coronavirus have already decreased by $60 \%$ and this figure is constantly growing. Urgent measures are required:

1. Deferral for all taxes except VAT for 6 months;

2. Extension of loan repayment terms for 6 months $-1 / 3$ is paid by the state, $1 / 3$ by the bank and $1 / 3$ by the borrower;

This is not just about postponing payments for six months, but about a full shift in all payments on the principal debt, in other words, each payment is postponed for six months.

3. For micro-enterprises, deferral of social fund insurance contributions;

4. For small and medium-sized enterprises, the rate for them is reduced by 2 times.

\footnotetext{
* Corresponding author: chupin al@pfur.ru
} 
According to Maxim Reshetnikov, Minister of Economic Development, due to these measures in the next six months, this business area will be free from payments for 125 billion rubles. This money will stay in business. In addition, loans and investments will be refinanced to ensure production.

Russian banks are ready to provide loans for entrepreneurs on preferential terms. In turn, the Bank of Russia provides banks with a line at a rate of $4 \%$ per year.

Quarantine throughout the state, self-isolation and mass transfer of employees by companies to a remote work format (remote work) is something completely new for Russia. But our state did not become lonely here, the coronavirus pandemic swept the whole world in a matter of weeks.

This hit business quite hard, and in many respects the economic situation in the United States and Europe is already comparable to the 2008 global financial crisis. Moreover, there is every reason to believe that in some industries the decline will be even greater. In the near future, the majority of Ukrainian entrepreneurs will fully feel this.

Small and medium-sized enterprises amid the new coronavirus infection. Which business will suffer more from the quarantine, and who will continue to develop? Russian business is now divided into two categories: some are suffering losses and are on the verge of bankruptcy, while others, on the contrary, are experiencing an unprecedented rise.

The most affected were cinemas, shopping centers, coworking spaces, fitness rooms, markets, cafes and restaurants, travel companies, sellers of building materials, companies that sell and manufacture furniture, cleaning business, private kindergartens, etc. That is, in fact everyone who was prohibited from working at the legislative level, who is focused on the flow of people or whose work involves personal contact with the client. And this is a large part of the service sector and offline retail.

For the tourism industry, dark times have come at all, because even after the end of quarantine, it is not known how long it will take for the market to recover to the level of the beginning of the epidemic.

On the other hand, delivery services, courier companies, online stores, services for remote work, and similar areas, the basis of the business model of which is a remote format of interaction and which are focused on the general population, are experiencing tangible growth, and in some cases even a real boom in demand. According to the analysis, there is also a significant increase in sales in such areas as:

- fitness products $(+250 \%)$

- goods for creativity $(+280 \%)$

- table games $(+156 \%)$

- books $(+40 \%)$.

Companies working in the field of information technology (IT), especially focused on foreign customers, also transferred workers to a remote mode of work without any problems. However, the global crisis does not bypass this niche either.

Medium and small projects tied to the real sector freeze investments in the development of new information solutions and move to keeping the system in working order. Accordingly, in companies that have a headcount without real projects, they expect a reduction.

According to forecasts, in a few months the IT sector expects a change in the direction of projects and, accordingly, the restoration of the dynamics of development.

Let's highlight a number of business support measures:

1. Subsidies to entrepreneurs. This means financial assistance to small and mediumsized businesses in May-June, i.e. payments of 12,130 rubles will be made for each employee.

2. Interest-free loans for salaries. Banks will lend to enterprises with the support of the Central Bank to pay salaries to employees. The loan will be provided at a rate of $0 \%$ for the 
first 6 months and 4\% for the next 6 months. This procedure applies only to enterprises that are part of SMEs, belonging in the main or additional type of activity to one of the industries recognized as affected by the coronavirus pandemic for other organizations belonging to the main type of activity.

3. Lease deferral. This measure implies a deferral of rent payments until October for public and commercial real estate for the affected industries.

4. Credit holidays. Implies a 6-month grace period for small and medium-sized enterprises affected by the coronavirus infection.

5. Credit holidays for citizens. This measure concerns citizens whose incomes have decreased by $30 \%$ or more. Banks provide a 6 -month grace period for mortgages and consumer loans.

A complete list of measures can be found on the website of the Government of the Russian Federation.

\section{Mathematical model of economic growth of small and medium-sized enterprises in the context of the spread of the coronavirus epidemic}

The theory of economic growth, one might say, complements the theory of economic equilibrium. The subject of the theory is the mathematical expression of the laws of reproduction and the study of the relationships between the main indicators that determine the rate of economic growth. Economic growth models provide only upper technological limits on growth indicators, which can be much better than the actual ones.

Let's consider the simplest model of economic growth using the example of small and medium-sized businesses. It is based on material described in [1],[2],[3],[4]. We will assume that small and medium-sized enterprises (hereinafter referred to as SMEs) are in a closed economy, i.e. in other words, the national income will increase. Speaking of "closed economy" means the territory of the country and the creation of products in it, i. e. national income (hereinafter - product). One half of the product will be used for human consumption and the rest will be accumulated through production. Let us denote by $\mathrm{P}$ the amount of production of the product per unit of time, $\mathrm{O}$ - the amount of consumption, and $\mathrm{N}$ - the accumulated part of the product. It turns out that by definition

$$
P=O+N
$$

The country's production is limited by its capacity B and is set by the production function. The production function for a given capacity determines the output according to the number of people employed in the farm $\mathrm{K}$. We obtain the production function:

$$
\begin{aligned}
& P-B f(x), \\
& x=\frac{K}{B} .
\end{aligned}
$$

If $\mathrm{K}$ is the number of jobs in the labor force at a power value $\mathrm{B}$, and

$$
x=\frac{K}{B}
$$

then we get properties from the production function:

$\mathrm{f}(0)=0, f^{\prime}\left(x^{\prime}\right)=1, f^{\prime}(x)>0, f^{\prime \prime}\left(x<0\right.$ при $x^{\prime} \geq x$.

The accumulative part of the product $\mathrm{N}$ will be used to compensate for the decrease in power due to the effect of coronavirus infection on enterprises. If the creation of a unit of 
new capacity absorbs q units of a fund-forming product, then the accumulation of q per unit of time creates L units of new capacity:

$$
q L=N
$$

The rate of change in production capacity is the sum of the rate of creation of new capacity $\mathrm{L}$ and the rate of capacity decrease due to the effect of coronavirus infection on enterprises. It turns out that the rate of decline in production capacity will be proportional to the value of production itself, and the proportionality coefficient $M$ estimates the rate of retirement of production capacity. We obtain the equation:

$$
B=L-M B
$$

The number of employed workers of SMEs will be considered given and growing over time at a constant rate $\beta$

$$
K=K_{0} e^{\beta t}
$$

где $\boldsymbol{K}_{\mathbf{0}}$ - given positive constant.

Let's move on to the new variables: $\boldsymbol{y}=\frac{\boldsymbol{P}}{\boldsymbol{B}}, \boldsymbol{j}=\frac{\boldsymbol{L}}{\boldsymbol{B}}, \boldsymbol{O}=\frac{\boldsymbol{O}}{\boldsymbol{B}}$.

The quantity y expresses the degree of power productivity, $\mathrm{j}$ is the reciprocal of the time of the power productivity process, $\mathrm{O}$ is the per capita consumption of the person employed in the economy. From equation (4) we obtain:

$$
\frac{B}{B}=j-M
$$

From (1), (2), (3) We obtain:

$\mathrm{Y}=\mathrm{f}(\mathrm{x})(6)$ and $\mathrm{f}(\mathrm{x})=\mathrm{qj}+\mathrm{Ox} .(7)$

Studying the partial solution of the system of the equations (5)-(7):

$$
\phi=\frac{B}{B} \text {. }
$$

In this solution $\mathrm{x}=\frac{\boldsymbol{K}_{\mathbf{0}}}{\boldsymbol{B}_{\mathbf{0}}}$ is constant.

Let us introduce the measure $\overline{\boldsymbol{b}}=\boldsymbol{b} \frac{\boldsymbol{B}}{\boldsymbol{P}}=\frac{\boldsymbol{q}}{\boldsymbol{\beta}}$, and call it the median product capital intensity, and $\mathrm{n}=\frac{\boldsymbol{N}}{\boldsymbol{p}}=\frac{\boldsymbol{q} \boldsymbol{L}}{\boldsymbol{P}}=\frac{\boldsymbol{q} \boldsymbol{j}}{\boldsymbol{y}}=\overline{\boldsymbol{b}} \boldsymbol{j}$ (8) let us call the share of accumulation in national income.

So, when the production sector works in full load and accumulates $(n=1)(\bar{b}=\boldsymbol{b})$, then

$$
M=\frac{1}{q}-M
$$

This is the highest limitation on growth rate. To allow the expansion of production, the condition should be fulfilled.

$$
1-M q>0
$$

\section{Results}

This condition has a clear meaning: at a time when there was no pandemic and all enterprises were operating at full capacity, a certain unit of the product was produced, and under the conditions of coronavirus infection, SMEs reduced production, i.e. its production 
capacity by $\mathrm{M}$ units. Consequently, condition (10) will express the significance for production, i.e. his productivity. In other words, SMEs operating at full capacity produced more product than during the pandemic. The net product per unit of power is equal to $1-\mathrm{Mq}$ per unit of time. In other words, it can be used for dynamic development of production capacity and for consumption.

From the obtained results of the formulas, it is possible to accumulate the rate that will ensure the maximum consumption per capita who is engaged in production:

$$
n_{m}=\frac{1-x_{m} f^{\prime}\left(x_{m}\right)}{f\left(x_{m}\right)}
$$

where $\boldsymbol{x}_{\boldsymbol{m}}$ denotes the solution

$$
x f^{\prime}(x)-f(x)+q(ß+M)-0 .
$$

- Value $\boldsymbol{n}_{\boldsymbol{m}}$ is denoted as a norm of the «golden rule of growth», given in (11).

- $\quad$ Speaking about business, the result of the development of coronavirus in Russia was the closure of all shopping centers, cinemas, concert halls, etc. almost $80 \%$ of the staff were unemployed. The Russian economy can be divided into two parts. The first part is the one that works for export - this part has at all times survived better than the Russian economy, which works on the domestic market. In the 21 st century, Russia's domestic economy is under the pressure of high interest rates, high tax pressure, and low demand. These are three factors that prevent the development of the Russian domestic market. If we take countries with low taxation such as Singapore, Taiwan, Hong Kong, India, America, then the economic growth of these countries will be much higher in comparison with the countries of Germany, France, England, Russia, since these countries have a very large tax burden on business. Instead of collecting about $40 \%$ from 100 trillion rubles in taxes, it is proposed to collect $30 \%$ from 150 trillion rubles by expanding the tax base. Analyzing the taxation of business in Russia, we can conclude that between taxes, i.e. the level of tax pressure on business and economic growth are inversely proportional. One of the main shocks today. This is an added value. For example, the iPhone is assembled in more than ten countries and these parts cross borders many times. But when we talk about the coronavirus crisis. Business gets hit hard because borders are closed, i.e. iPhones are not being assembled or sold, and the demand for iPhones is also declining, because people are not ready to spend money on a phone. they want to use this money and spend on living during the crisis.

The coronavirus has again forced monetary policy to ease. The Fed has cut the base rate despite the fact that it does so earlier than everyone expected. Now the range is from 0 to $0.25 \%$ and the American regulator promises to keep it at this level until the economy stabilizes. Together with the FRS, they promised to act together: Bank of Canada, Bank of England, Bank of Japan, Swiss National Bank, European Central Bank.

Italy has introduced one of the toughest quarantines in Europe, 350 thousand restaurants have been closed in Italy, and the country may also lose millions of tourists visiting it, which is $13 \%$ of GDP. Despite the fact that the Italian economy in recent years has not felt the best way, since Italy's public debt is 2 trillion 400 billion euros, which is $135 \%$ of GDP, a quarter of this amount is held by commercial banks and if the Government does not cope with obligations, then a recession in the economy is inevitable. If the situation with the coronavirus lasts until June, then the losses could amount to 275 million euros. Another scenario, if this situation continues until the end of the year, the borders with other states are closed, then losses could reach about 640 million euros.

There are also problems in the German economy. In Germany, 56\% of companies have encountered difficulties, in tourism $96 \%$ of entrepreneurs complain. For entrepreneurs in 
the field of tourism, the main source of income is not young people who like to save money, but traveling retirees, that category of people who are currently at risk.

China, in contrast to Europe, is beginning to come to a more stable position. In China, most construction companies have gone bankrupt as apartment sales in China have plummeted and developers have no money left to finance construction projects. In January and February, 105 companies filed for bankruptcy. Over the entire 2019, 500 Chinese companies left the market, that is, the problems in the industry began even before the pandemic. Construction companies were forced to quarantine workers both at civil construction sites and at infrastructure construction sites, with the exception of several facilities that were being built in Wuhan and in the Beijing area, in particular, hospitals and factories that produce masks that produce special equipment for medical needs.

\section{Conclusion}

Thus, the world economy has not yet had time to recover from many other crises such as the financial crisis, the "eurozone crisis", as for the coronavirus, this virus has further exacerbated the situation. It is becoming clear that the strategy of the past 30 years for solving crisis problems with cheap money and increasing the volume of loans can no longer work. Despite the large sums that are being talked about, it is unlikely that fiscal and monetary policies are coordinated, i.e. there is coordination between the heads of state, as was the case in 2008. To solve a global problem, a global approach is needed. Less than $10 \%$ of business leaders considered the likelihood of a pandemic in their risk scenarios, and less than half have tested their team for remote work at least once. Small and medium-sized businesses run the risk of going bankrupt very quickly. The speed of state aid allocation in such conditions becomes a very important parameter. This is why leading economists are urging governments to act quickly. From the point of view of maintaining aggregate demand, the main thing is the size of state support, that is, how much the government will be ready to increase its spending. The size of this increase should be roughly equal to the expected decline in GDP due to the crisis. At the moment, the exact scale of the economic decline is difficult to assess, but one can proceed from an estimate of $10 \%$ of GDP. There is a massive layoff in the world, a sharp increase in loan debt, an increase in the homeless, the inevitability of social conflicts, as a result of which the consequences of the coronavirus will be felt for many decades to come.

The paper has been supported by the RUDN University Strategic Academic Leadership Program.

\section{References}

1. Zh. Lemesheva, O. Yurchenko, M. Karpovich, Z. Petrikova, N. Bratishko, L. Garipova. Formation of an effective management structure for enterprises in the energy sector of the economy, E3S Web of Conferences 110, 0 (2019) https://doi.org/10.1051/e3sconf /201911002129

2. Zh. Lemesheva, L. Lavrova, N. Chernegov, M. Ivanova, E. Akimova. Development of the mechanism of motivation and tangible incentivisation, January 2018 MATEC Web of conferences 170(2):01094 doi:10.1051/matecconf/201817001094;

3. A. Chupin, O. Yurchenko, Zh. Lemesheva, A. Pak, M. Khudzhatov. Development of Logistical Technologies in Management of Intellectual Transport Systems in the Russian Federation, Part of the Lecture Notes in Networks and Systems book series (LNNS, volume 87). Digital Economy: Complexity and Variety vs. Rationality pp 778784 
4. V.G.Anisimov, E.G.Anisimov, A.Yu.Pak, T.N.Saurenko, Zh.S. Chupina, A.L.Chupin, Methodological provisions for digitalization of control activities of customs authorities. All-Russian scientific and analytical journal "Financial Economics" 4, 6-11 (2020) ISSN 2075-7786. 